
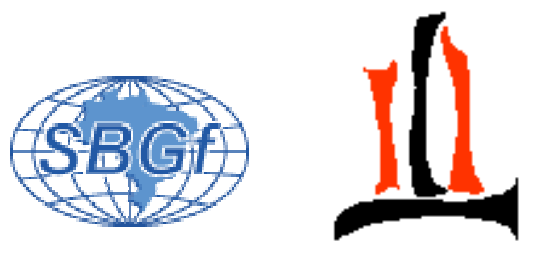

São Paulo 2004

\title{
BLSP02: Projeto de Estudo Sismológico da Crosta e Manto Superior no Brasil
}

\author{
Marcelo Assumpção, Mei Feng, Eduardo Mandel, José Roberto Barbosa, Marcelo Bianchi, (IAG-USP, São Paulo) \\ Suzan Van der Lee, Federica Marone \& Mark van der Meijde (Instituto de Geofísica, ETH-Zurich, Suíça).
}

Copyright 2004, SBGf - Sociedade Brasileira de Geofísica

Este texto foi preparado para a apresentação no I Simpósio Regional da Sociedade Brasileira de Geofísica, São Paulo, 26-28 de setembro de 2004. Seu conteúdo foi revisado pela Comissão Tecno-científica do I SR-SBGf mas não necessariamente representa a opinião da SBGf ou de seus associados. E proibida a reprodução total ou parcial deste material para propósitos comerciais sem prévia autorização da SBGf.

\section{Abstract}

The recent Brazilian Lithosphere Seismic Project (BLSP02) is studying the crustal and upper mantle structure in Brazil by operating broadband seismic stations in areas not covered in previous studies, specially in Northern and NE Brazil. Teleseismic $P$ waves are being used to investigate crustal structure with receiver functions, and surface waves are being used in tomographic mapping of the lithosphere. As an example, the crustal thickness beneath the Teresina station is shown to be $40 \mathrm{~km}$. Preliminary results of joint inversion of Rayleigh wave group velocities and waveforms reveal new features: thick lithosphere of the SE part of the Amazon craton, and upper mantle low velocity anomalies beneath the Pantanal Basin. Regional and local seismicity are also studied with the new stations. This is a multi-institutional project with collaboration from universities (UnB, UFRN, UFMS, UFRA and IPT) and logistical support from several companies (CPRM, Anglo-Gold, CVRD, De Beers, RTDM, Embasa, and Alta Resolução).

\section{Introdução}

O Brasil é um dos países onde a estrutura profunda da crosta e manto superior é muito pouco conhecida. $O$ baixo número de estações sismográficas, principalmente nas regiões norte e nordeste, não tem permitido mapeamentos da litosfera com boa resolução. No Sudeste do Brasil estudos recentes da crosta (Assumpção et al., 2002; França \& Assumpção, 2003) mostraram, por exemplo, que a Bacia do Paraná tem crosta mais espessa do que as faixas de dobramentos brasilianas, resultado contrário ao que se costuma esperar pela topografia e anomalias gravimétricas. Tomografia do manto superior (Schimmel et al., 2003; Rocha \& Assumpção, 2004; Feng et al., 2004; Assumpção et al., 2004a) vem revelando importantes estruturas profundas, como por exemplo anomalias de baixa velocidade sísmica sob as províncias de intrusões ígneas do Cretáceo Superior que podem ser interpretadas como afinamentos litosféricos. O projeto BLSP02 (Brazilian Lithosphere Seismic Project - 2002) visa complementar a cobertura de estações no norte e nordeste do Brasil para melhorar o mapeamento da crosta e litosfera no país.

\section{Rede Sismográfica}

A Fig. 1 mostra as estações sismográficas instaladas no projeto BLSP02. Triângulos azuis são estações com equipamentos do IAG-USP (RefTek com registros contínuos a 10 aps, e registro com gatilho a 50 ou 100aps), triângulos vermelhos são estações suíças (MARS88 com registro contínuo a 31aps). Ambas têm sismômetro banda-larga STS-2 para registrar tanto ondas de período longo de terremotos distantes (até $100-150$ s), como ondas de frequência mais alta de pequenos sismos regionais (até $\sim 10 \mathrm{~Hz}$ ). Os quadrados amarelos são estações da UnB (da rede Amazonscope) com sensores Guralp de 30s. Triângulos brancos são estações de estudos anteriores, a maior parte já desativada.

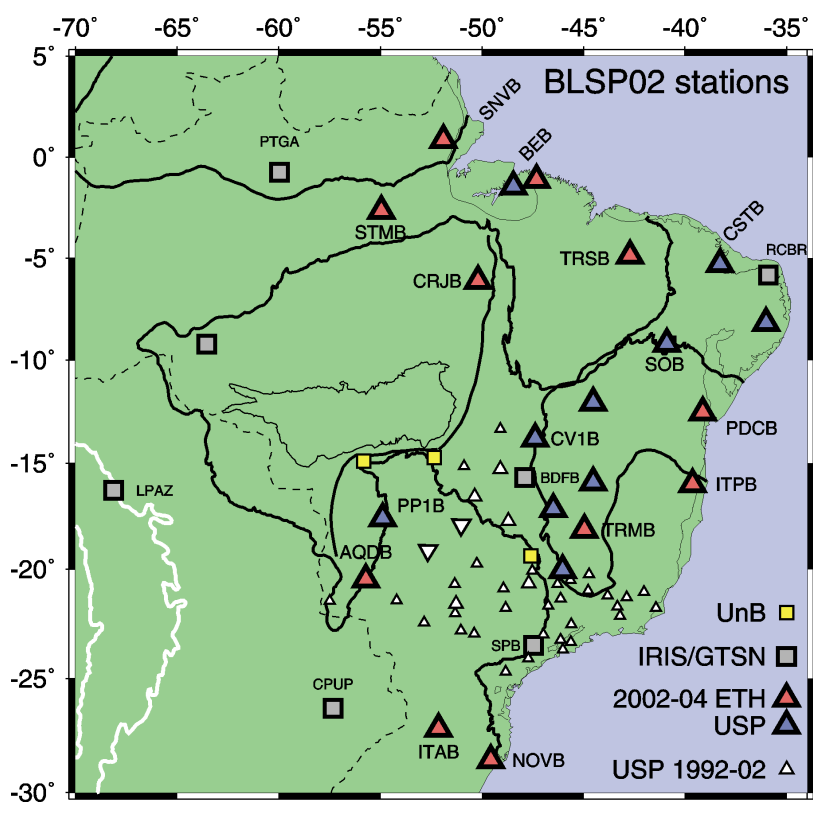

Fig. 1. Estações BLSP02: triângulos vermelhos e azuis são estações temporárias de ETH e do IAG-USP, respectivamente, com sismômetros de banda larga (até 120s). Quadrados amarelos são estações da UnB de banda intermediária (até 30s). Quadrados cinza são estações da rede mundial (IRIS, GTSN, Geoscope). Triângulos brancos são estações desativadas de projetos anteriores; os dois triângulos brancos invertidos são estações instaladas em julho de 2004.

Fig. 1. BLSP02 stations: red and blue triangles are ETH and USP stations with STS-2 sensors; yellow squares are UnB stations with Guralp-30s; white triangles are deactivated stations from previous projects; inverted triangles are IAG stations installed in July 2004 


\section{Espessura da crosta com função do receptor}

A análise das componentes horizontais e verticais da onda $\mathrm{P}$ de sismos distantes (telessismos), permite identificar as ondas $P$ (longitudinais) convertidas em $S$ (cisaIhantes) nas várias interfaces da crosta e principalmente na descontinuidade Moho (interface crosta-manto). Esta técnica, chamada "função do receptor", baseia-se na deconvolução da componente radial pela vertical, o que elimina a assinatura da fonte e deixa apenas as ondas $S$ como se fossem originadas de um pulso de onda $P$ incidente na base da crosta. A Fig. 2 mostra um esquema das ondas Ps e PpPms que seriam observadas em uma crosta uniforme sem descontinuidades internas.

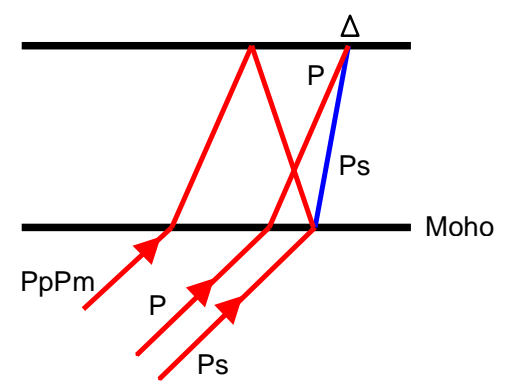

Fig. 2. Raios das fases $P$ direta, conversão Ps, e múltipla PpPms. Linhas vermelhas são ondas $P$ e azul onda $S$. Fig. 2. Ray diagram for the direct $P$ wave, $P$ s conversion and PpPms multiple. Red lines are $P$ wave, blue is $S$ wave.

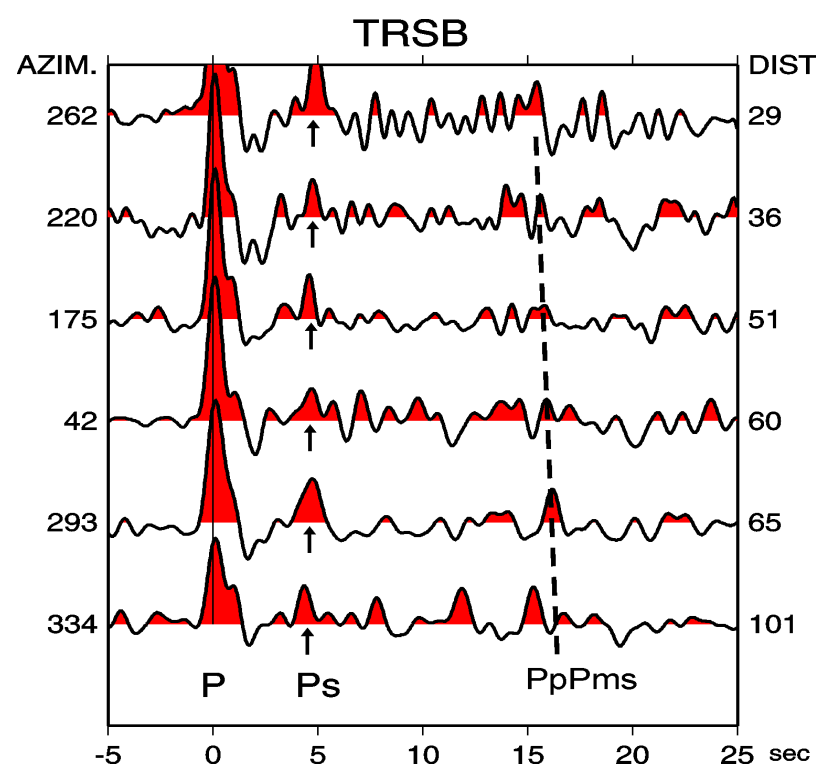

Fig. 3. Funções do receptor para TRSB (Teresina, PI). A distância epicentral e o azimute de chegada (em graus) estão indicados à esquerda e à direita, respectivamente. $\mathrm{P}$ é a onda direta, Ps a conversão de $\mathrm{P}$ a $\mathrm{S}$ na interface crosta-manto, e PpPms a reflexão múltipla. As setas indicam a posição esperada da Ps para uma crosta de $40 \mathrm{~km}$ de espessura. Note a diminuição do tempo Ps-P com o aumento da distância epicentral.

Fig. 3. Receiver functions for TRSB with gauss filter 3. Arrows indicate the expected Ps times for a $40 \mathrm{~km}$ thick crust. Numbers on each side are backazimuths and epicentral distances.
A Fig. 3 mostra as funções do receptor na estação TRSB (Teresina, PI) calculadas com seis telessismos de distâncias e azimutes diferentes. A onda Ps (conversão de $P$ para $S$ na base da crosta) é bem clara; a onda PpPms (reflexão múltipla) é mais difícil de identificar, mas técnicas de empilhamento mostram que esta reflexão é o pico positivo indicado pela linha tracejada. A diferença de tempo Ps-P diminui com a distância epicentral, já a diferença PpPms-P aumenta com a distância, propriedades estas que auxiliam na identificação das duas fases.

Os tempos das ondas PpPms e Ps permitem calcular o valor médio da razão $\mathrm{Vp} / \mathrm{Vs}$ na crosta sob a estação TRSB como sendo 1,71. Supondo uma velocidade média da onda $P$ na crosta de $V p=6,4 \mathrm{~km} / \mathrm{s}$, a espessura crustal resulta em $40 \mathrm{~km}$.

O método da função do receptor está sendo usado em todas as estações do projeto não apenas para determinar as espessuras crustais mas também para estimar as espessuras das camadas sedimentares. Por exemplo, a Fig. 3 mostra que o pico da onda $P$ direta é largo e tem um pequeno pico secundário no tempo de 1s aproximadamente. Este pico corresponde a conversões ou múltiplas nas camadas sedimentares e pode ser usado para estimar a profundidade do embasamento, como feito por An \& Assumpção (2004).

\section{Ondas de superfície}

Ondas de superfície de telessismos estão sendo usadas para mapear variações na espessura da litosfera. A Fig. 4 mostra os registros das ondas de superfície Rayleigh de um sismo do Peru em quatro estações. Note a dispersão característica das ondas de superfície em que os períodos maiores chegam antes que os períodos menores, por terem maior velocidade de propagação.

\section{velocidade de grupo}

A velocidade com que a energia de cada período chega à estação, chamada velocidade de grupo, pode ser calculada por filtragens múltiplas. A determinação destas velocidades de grupo (média entre cada epicentro e estação) para as centenas de sismos registrados permite um mapeamento regionalizado destas velocidades, como feito por Feng et al. (2004). Como exemplo, a Fig. 5 mostra as velocidades de grupo para o período de 20 s das ondas Rayleigh. Estas velocidades dependem de vários fatores (espessura dos sedimentos, espessura da crosta, etc.). A velocidade de grupo para 20 s depende do perfil de velocidades da onda $\mathrm{S}$ até $\sim 30 \mathrm{~km}$, aproximadamente. $\mathrm{Na}$ Fig. 5 vê-se o efeito das bacias intracratônicas.

Períodos maiores amostram profundidades maiores da crosta e manto. Com as velocidades de grupo para vários períodos (amostrando profundidades diferentes), pode-se determinar o perfil de velocidades da onda S na crosta e manto superior, como feito por Feng et al. (2004). A Fig. 6 mostra a velocidade da ondas $S$ a $30 \mathrm{~km}$ de profundidade (crosta inferior) onde se nota que a bacia do Paraná tem velocidades menores (provavelmente densidades mais baixas) que as faixas de dobramento circundantes. 

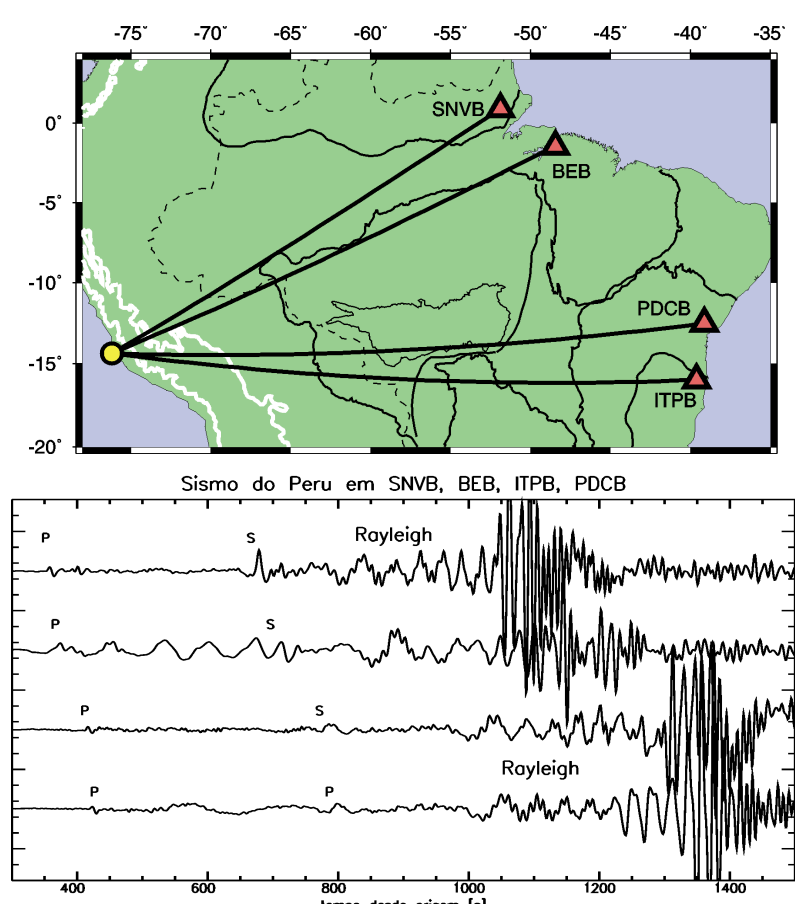

Fig. 4. Trajetórias e sismogramas do sismo do Peru ocorrido em 01.11 .2002 , às $05: 04$, com magnitudes $5,3 \mathrm{mb}$ e $4,8 \mathrm{Ms}$. P é a primeira onda (longitudinal), S é a onda transversal, e Rayleigh é o trem de ondas superficiais.

Fig. 4. Paths and seismograms for the Peru event of 2002 November 11, 05:04, with magnitudes 5,3 $\mathrm{mb}$ and 4,8 Ms.

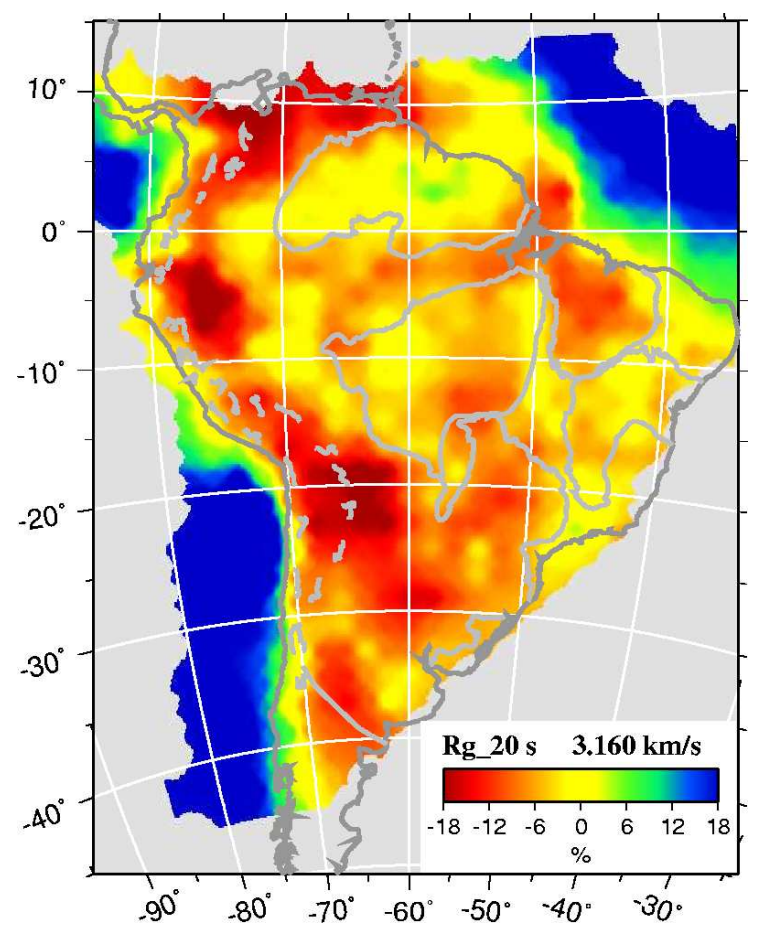

Fig. 5. Velocidades de grupo, onda Rayleigh de $20 \mathrm{~s}$. Valores maiores nos oceanos devem-se à menor espessura crustal. Nas bacias intracratônicas os sedimentos abaixam a velocidade.

Fig. 5. Rayleigh wave group velocities for 20 s period. Note effect of intracratonic basins.

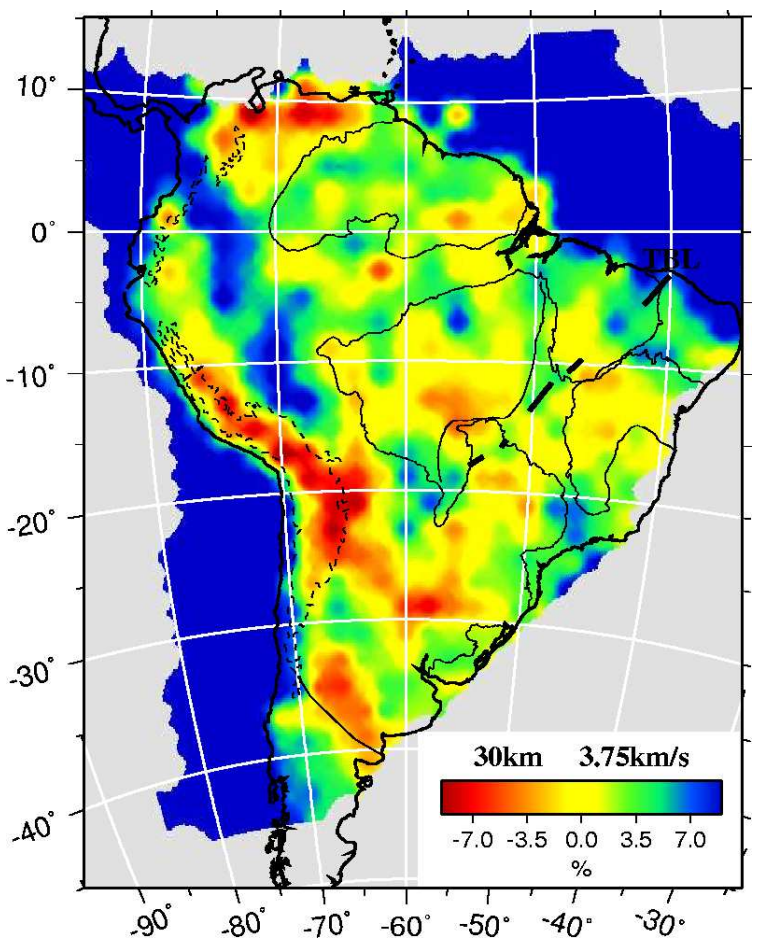

Fig. 6. Velocidades da onda $S$ a $30 \mathrm{~km}$ de profundidade (crosta inferior). Escala de cores refere-se às variações em torno de $3,75 \mathrm{~km} / \mathrm{s}$. Note velocidades baixas no meio da Bacia do Paraná.

Fig. 6. S-wave velocities at $30 \mathrm{~km}$ depth, from inversion of regionalized dispersion curves. Note low values in the Paraná basin.

\section{modelagem da forma de onda}

Tomografia com velocidade de grupo de ondas de superfície não tem a mesma resolução que tomografia por modelagem dos sismogramas. A Fig. 7 mostra um exemplo de modelagem do perfil de velocidades da onda $S$ na crosta e manto superior entre o epicentro do sismo do Peru (Fig. 4) e a estação SNVB (Serra do Navio, AP). Esta modelagem indicou altas velocidades entre $100 \mathrm{e}$ $200 \mathrm{~km}$ de profundidade, provavelmente porque a maior parte do percurso está no cráton amazônico (Fig. 4).

$\mathrm{O}$ perfil de velocidade da Fig. 7b é uma média de todo o percurso entre epicentro e estação. A modelagem de centenas de sismogramas cruzando toda a plataforma sul-americana (trabalho em andamento) permitirá uma inversão tomográfica 3D com resolução bem melhor do que a obtida com as velocidades de grupo.

Tomografia com forma de onda já foi realizada na América do Sul por Van der Lee et al.(2001) e Heintz et al.(2004), mas sem uma boa cobertura de percursos no norte e nordeste do Brasil. Os dados do projeto BLSP02 permitirão mapear com mais precisão as grandes estruturas litosféricas em todo o Brasil. 
a)

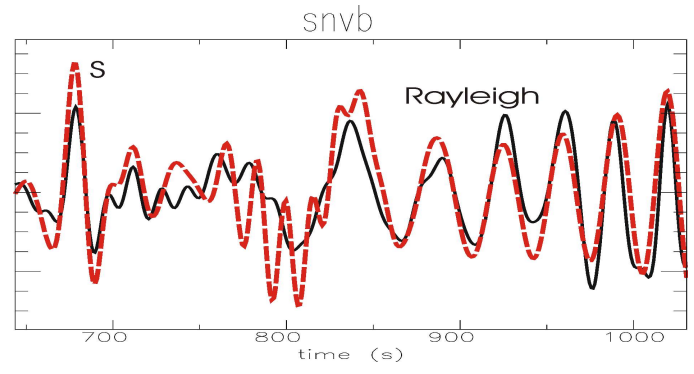

b)

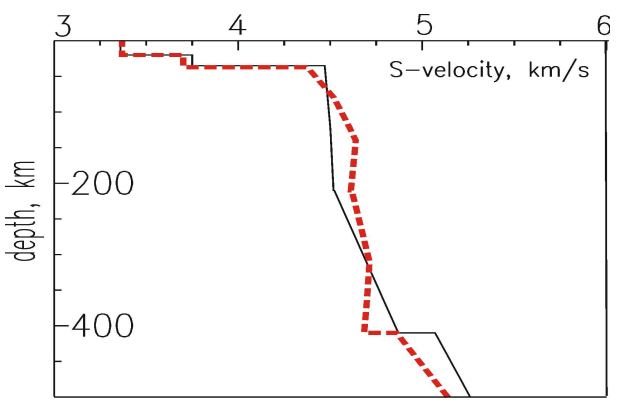

Fig. 7. Modelagem do sismo do Peru na estação SNVB (Fig. 4). a) comparação entre sismograma observado (linha contínua) e sismograma calculado (linha vermelha tracejada). b) perfil de velocidades da onda S: linha contínua é o modelo médio global IASP91, usado como perfil inicial na modelagem; linha vermelha tracejada é o modelo 1D obtido para o percurso epicentro-SNVB.

Fig. 7. a) observed (solid line) and synthetic (dashed red line) seismograms. b) initial IASP91 model (solid line) and calculated $1 D$ model (dashed red line) for the path epicenter-SNVB shown in Fig. 4.

\section{Tomografia e espessura da litosfera}

Uma nova metodologia está sendo desenvolvida para inversão conjunta de velocidades de grupo e modelagem de sismogramas. Velocidades de grupo podem ser medidas com sismos de menor magnitude sem mecanismo focal conhecido. Por isso, apesar de ter resolução menor que o modelamento de sismogramas, velocidades de grupo trazem infomações importantes na determinação das estruturas da crosta e manto superior. Uma inversão preliminar já foi realizada com $\sim 6.000$ dispersões de velocidade de grupo e $\sim 1000$ modelagens de sismogramas. A Fig. 8 mostra o resultado da velocidade da onda S a 150 $\mathrm{km}$ de profundidade. Áreas verdes e azuis (maiores velocidades) indicam maiores espessuras da litosfera.

$\mathrm{Na}$ região andina, as altas velocidades no Peru (entre $5^{\circ} \mathrm{S}$ e $\left.13^{\circ} \mathrm{S}\right)$ e na Argentina $\left(\sim 30^{\circ} \mathrm{S}\right)$ mostram o segmento horizontal ("flat subduction") da placa de Nazca.

A região do cráton amazônico é caracterizada por velocidades altas correspondendo a maiores espessuras litosféricas. A parte leste do cráton, mais antiga (província $A$, $>2.3 \mathrm{Ga}$ ), tem espessuras maiores que a parte oeste (província D, 1.8-1.5Ga), de acordo com as províncias geocronológicas de Tassinari \& Macambira (1999).

O cráton do São Francisco, principalmente sua parte sul e extensão sob os metassedimentos de baixo grau

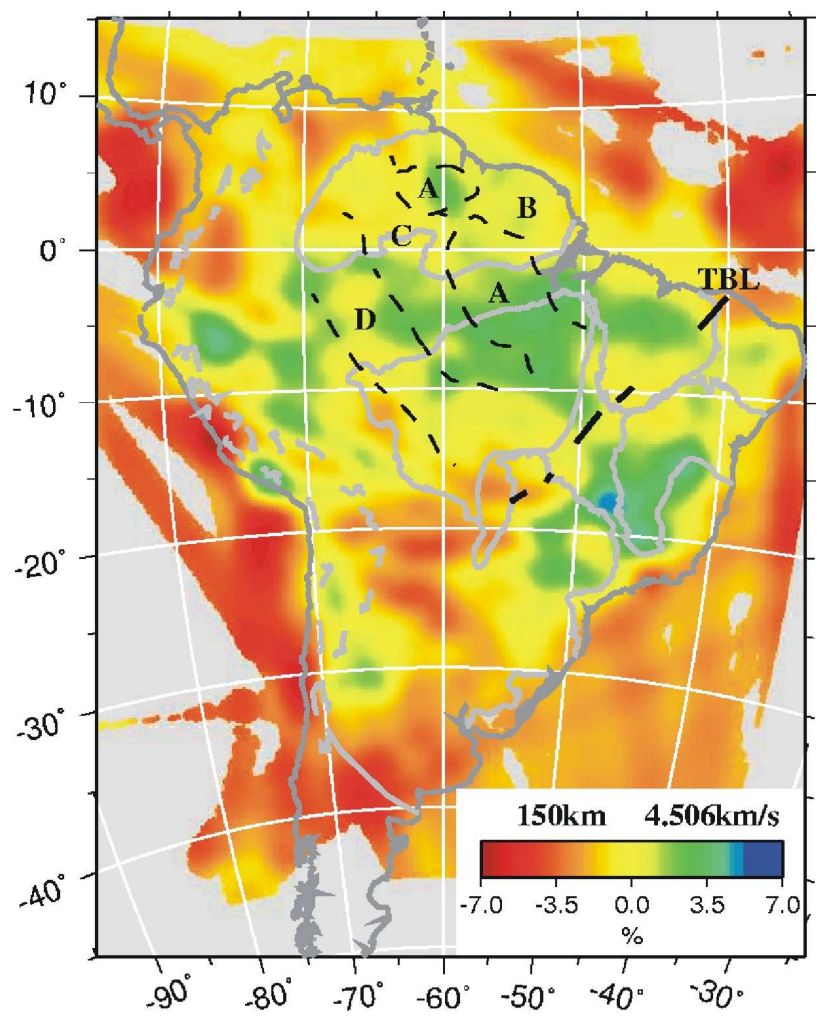

Fig. 8. Modelo de velocidades da onda $S$ a $150 \mathrm{~km}$ de profundidade, obtido com inversão conjunta de forma de onda e velocidades de grupo da onda Rayleigh (modelo preliminar). Áreas verdes e azuis (maior velocidade) correspondem a maior espessura da litosfera. Províncias geocronológicas do cráton amazônico são indicadas por letras A (>2.3Ga) a D (1.8-1.5Ga).

Fig. 8. S-wave velocity model at $150 \mathrm{~km}$ depth from joint inversion of Rayleigh wave group velocities and waveform data (preliminary result). Large velocities correspond to thicker lithosphere. Amazon craton geochronological provinces are indicated by letters $A$ (oldest) to $D$ (youngest) .

(domínio "foreland") da faixa de Brasília, também é caracterizado por altas velocidades e maiores espessuras. Esta continuação para oeste do cráton do São Francisco em profundidade foi observada também por Assumpção et al. (2004b) com base em tomografia de ondas $P$ e propriedades médias da razão Vp/Vs crustal.

É interessante notar que sob as bacias do Paraná e do Parnaíba, altas velocidades são compatíveis com núcleos cratônicos, como proposto por alguns autores, o que poderia explicar a baixa sismicidade intraplaca nestas bacias (Assumpção et al., 2004a).

Uma anomalia de baixa velocidade encontra-se sob a Bacia do Pantanal e Bacia do Chaco, já detectada anteriormente por outros estudos (Van der Lee et al., 2001; Heintz et al., 2004).

A Fig. 9 compara as velocidades da onda $P$ a $150 \mathrm{~km}$ de profundidade (tomografia de Rocha \& Assumpção, 2004) com as velocidades da onda $S$ (modelo 3D, Fig. 8). A tomografia da onda $P$ foi feita com uma grade de pontos espaçados de $\sim 40 \mathrm{~km}$, ao passo que o da onda Rayleigh 
tem um espaçamento de $\sim 400 \mathrm{~km}$. Assim, as anomalias negativas da onda $\mathrm{P}$ bem concentradas em áreas pequenas ( $200 \mathrm{~km}$ de diâmetro) não são detectadas pela tomografia Rayleigh. Apesar da diferença de resolução, os dois mapeamentos mostram padrões regionais similares: maiores velocidades no meio da Bacia do Paraná e no cráton do São Francisco, indicando maiores espessuras da litosfera nestas áreas.

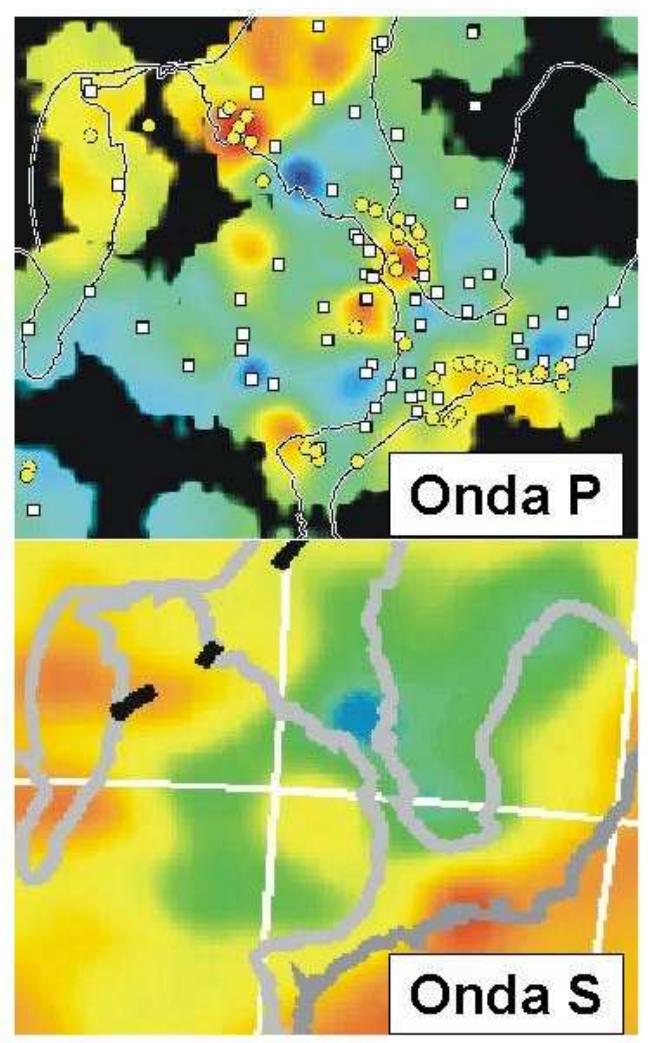

Fig. 9. a) velocidades da onda $P$ a $150 \mathrm{~km}$ de profundidade (tomografia de Rocha \& Assumpção (2004) com grade de espaçamento de $\sim 40 \mathrm{~km}$ ). As variações são da ordem $+-1 \%$; quadrados brancos são as estações usadas; círculos amarelos são intrusões alcalinas do Cretáceo Superior. b) velocidades da onda $\mathrm{S}$ a $150 \mathrm{~km}$ de profundidade obtidas com ondas Rayleigh (Fig. 8), com grade de $\sim 400 \mathrm{~km}$; variações da ordem de $+-5 \%$. Cores azuis são velocidades maiores, cores vermelhas velocidades menores

Fig. 9. Comparison of P-wave (a) and S-wave (b) velocities in the lithospheric lid. Blue and red colors are higher and lower velocities, respectively. a) teleseismic $P$-wave tomography at $150 \mathrm{~km}$ depth using previous stations (white squares); gridspacing about $40 \mathrm{~km}$; anomaly range is about $+-1 \%$. b) $S$ velocities at $150 \mathrm{~km}$ depth obtained by inversion of Rayleigh waves (fig. 8) with a grid spacing of $4^{\circ} \times 4^{\circ}$; anomaly range is about $+-5 \%$. Negative $P$ anomalies in concentrated areas (< $200 \mathrm{~km}$ ) cannot be detected by the surface-wave tomography, but the regional patterns are reasonably consistent.

\section{Sismicidade regional}

Além de estudos de estrutura da crosta e manto superior, o projeto BLSP02 vem registrando vários sismos regionais, como exemplificado nas figuras 10 a 12, contribuindo para um melhor conhecimento da sismicidade do Brasil.

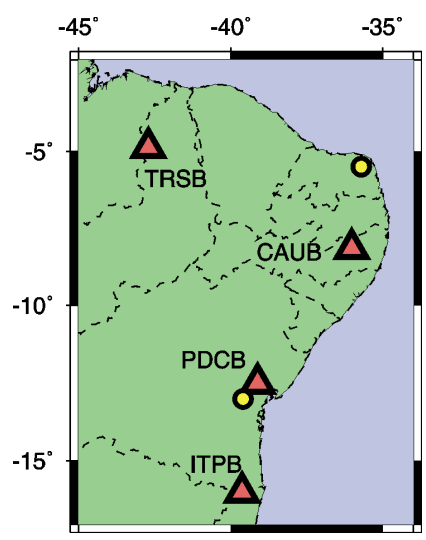

Fig. 10. Sismos de Amargosa, BA, de 10/10/ 2002, e de João Câmara, $\mathrm{RN}$, de $26 / 02 / 2003$ (círculos amarelos) e estações (triângulos vermelhos).

Fig. 10. Epicenters of regional earthquakes (yellow circles) and seismic stations (red triangles).

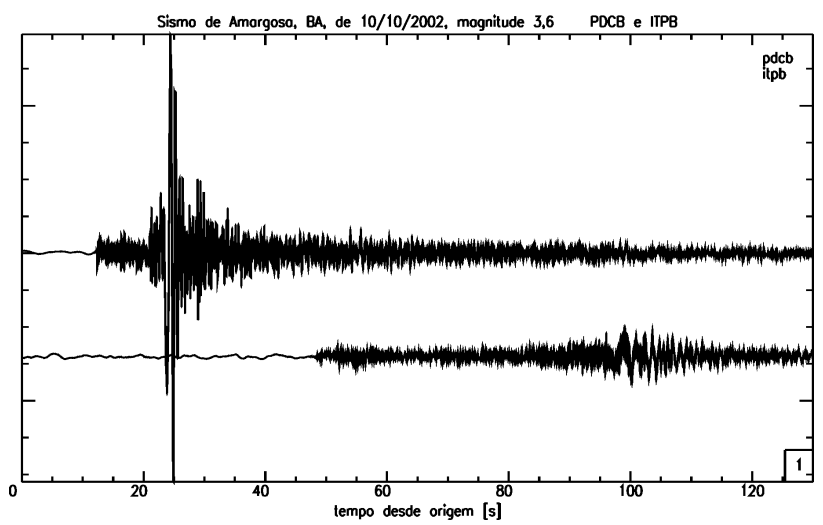

Fig. 11. Registros do sismo de Amargosa,BA, de magnitude 3,5 mb, em Pedra do Cavalo (PDCB) e Itapebi (ITPB), BA.

Fig. 11. Records from the earthquake in Amargosa, $B A$, magnitude 3,5 mb, at Pedra do Cavalo (PDCB) and Itapebi (ITPB) stations.

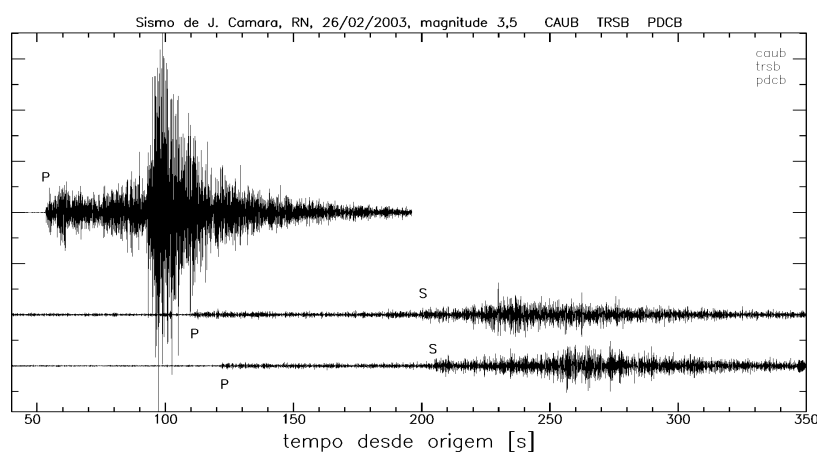

Fig. 12. Sismogramas do sismo de João Câmara, RN, magnitude 3,6 mb, registrado em Caruaru (CAUB), Teresina (TRSB) e Pedra do Cavalo (PDCB) .

Fig. 12. Seismograms from earthquake in João Câmara, RN, magnitude 3,6 mb, recorded at Caruaru (CAUB), Teresina (TRSB) and Pedra do Cavalo (PDCB). 


\section{Instituições participantes}

Várias instituições estão participando do projeto BLSP02. O Observatório Sismológico da UnB contribui com os dados de suas estações de banda intermediária para tomografia de onda $\mathrm{P}$ no Sudeste e função do receptor. O grupo de Sismologia do Depto. de Física da UFRN opera as estações de Caruaru, PE, e Castanhão, CE. A Universidade Federal Rural da Amazônia (UFRA) operou a estação de Igarapé-Açu, PA. O Depto. de Geociências da UFMS-Aquidauana opera a estação AQDB. O IPTSão Paulo contribuiu com a operação da estação de Itá, SC. As seguintes empresas colaboraram com a logística e operação de várias estações: Anglogold com a estação em Serra do Navio, AP; Rio Tinto Desenvolvimento Minerais em Santarém, PA; CVRD em Carajás, PA; CPRM em Teresina, PI; DeBeers em Três Marias, Januária, MG, e em Correntina, BA; Embasa em Pedra do Cavalo, BA; Itapebi/UnB em ITPB, BA; e Alta Resolução com as estações NOVB e PP1B.

\section{Conclusões}

O projeto BLSP02 coletou uma grande quantidade de dados sismológicos que estão sendo utilizados para um melhor mapeamento das grandes unidades da litosfera no Brasil. Resultados preliminares das ondas de superfície (Feng et al., 2004) são animadores e indicam que a tomografia de forma de onda deverá mapear com boa resolução as regiões norte e nordeste do Brasil, principalmente integrando-a com dados de velocidade de grupo das ondas superficiais.

A tomografia de onda $P$ do manto superior sob o SE e Centro-Oeste deverá ter sua cobertura densificada com as novas estações recentemente instaladas em Mato Grosso do Sul e Goiás.

\section{Agradecimentos}

Este projeto tem apoio do Fundo Setorial Mineral/MCT, da FAPESP (Auxílios 96/01566-0, 01/06066-6, e 02/ 00244-2), do CNPq (bolsa 30.927/95 e Auxílio Integrado 52.0078/00-4) e do Instituto de Geofísica da ETHZurique, Suíça (grant 0-20990-02). Agradecemos a Domenico Giardini e Edi Kissling (ETH) pelo empréstimo de dez estações sismográficas de banda-larga.

\section{Referências}

An, M. \& M. Assumpção, 2004. Basement depth in the Paraná Basin with high frequency receiver functions. I Simpósio de Geofísica da SBGf, São Paulo, 09/2004.

Assumpção, M., M. Schimmel, C. Escalante, M. Rocha, J.R. Barbosa \& L.V. Barros, 2004a. Intraplate seismicity in Brazil: stress concentrations in lithospheric thin spots. Geophys.J.Int., in press.

Assumpção, M., M. An, M. Bianchi, G.S.L. França, M. Rocha, J.R. Barbosa \& J. Berrocal., 2004b. Seismic studies of the Brasília Fold Belt at the western border of the São Francisco craton, central Brazil, using receiver function, surface wave dispersion, and teleseismic tomography. Tectonophysics, in press.

Assumpção, M., D. James \& A. Snoke, 2002. Crustal thicknesses in SE Brazilian shield by receiver function analysis: implications for isostatic compensation. $J$. Geophys. Res., 107, ESE2-1-ESE2-14, 10.1029/2001JB000422.

Feng, M., M. Assumpção \& S. van der Lee, 2004. Group-velocity tomography and lithospheric S-velocity structure of the South American continent. Phys. Earth Planet. Int., submitted.

França, G. \& M. Assumpção, 2003. Estrutura da crosta em Goiás, usando a função do receptor, e mapa preliminar de espessuras crustais no SE e centro-oeste do Brasil. VIII Congr. da SBGf, Rio de Janeiro, CD-ROM.

Heintz. M., E. Debayle \& A. Vauchez, 2004. Upper mantle structure of the South American continent and neighboring oceans from surface wave tomography. Tectonophysics, submitted.

Van der Lee, S., D. James \& P. Silver, 2001. Uppermantle S-velocity structure under South America. J.Geophys.Res. , 106, 30821-30834.

Rocha, M, \& M. Assumpção, 2004. Tomografia sísmica do manto superior no Brasil utilizando ondas P. I Simpósio de Geofísica da SBGf, São Paulo, CD-ROM.

Schimmel, M., M. Assumpção \& J. VanDecar, 2003. Upper mantle seismic velocity structure beneath SE Brazil from P- and S-wave travel time inversions. J. Geophys. Res., 108(B4), 2191, doi:10.129/2001JB000187.

Tassinari, C.C.G. \& M.J.B. Macambira, 1999.

Geochronological provinces of the Amazonian Craton. Episodes 22(3), 174-182. 